\title{
O Sistema Único de Assistência Social e os trabalhadores na Política Nacional Assistência social: um enfoque às terapeutas ocupacionais
}

The Unified System of Social Assistance and workers in the National Social Assistance Policy:

a focus on occupational therapists

Marina Leandrini de Oliveira*

Ana Paula Serrata Malfitano**

\section{Resumo}

Compreendendo as diferentes possibilidades de atuações profissionais que podem compor as equipes do Sistema Único de Assistência Social (SUAS) para contribuir com a proteção social, delineou-se o objetivo: identificar, descrever e analisar características da inserção e práticas de terapeutas ocupacionais em unidades do SUAS. Organizou-se os procedimentos metodológicos em duas etapas: levantamento dos profissionais vinculados à assistência social (Censo SUAS) e descrição e análise de sua inserção e práticas, estruturados em três fontes de dados: questionários online $(n=241)$, entrevistas (10) e visitas a unidades (quatro). Os resultados apontaram que os dados do Censo SUAS e das respostas provenientes dos questionários online se mostram congruentes em características de inserção nacional dos terapeutas ocupacionais. As práticas identificadas nas diferentes etapas, abarcaram: acolhidas, acompanhamentos individuais, familiares, visitas domiciliares, articulação em rede e grupos/oficinas. Foram elaboradas três categorias de análises sobre as características do trabalho de terapeutas ocupacionais no SUAS. Espera-se que a caracterização sobre as práticas de trabalhadores da assistência social, como aqui especificada de terapeutas ocupacionais, possa oferecer subsídios para a qualificação dos caminhos de intervenção para a totalidade de categorias que integram a assistência social como executores da política de proteção social.

Palavras-chave: Terapia ocupacional social; Política social; Prática profissional; Sistema único de assistência social.

\begin{abstract}
Understanding the different possibilities of professional activities that can compose the teams of the Unified Social Assistance System (SUAS), to contribute to social protection, this study aimed to: identify, describe and analyze characteristics of insertion and practices of occupational therapists in SUAS. The methodological procedures were organized in two stages: survey of the number of professionals working in the SUAS and description and analysis of their insertion and practices, with three data sources: online questionnaires $(n=241)$, interviews (10) and visits to work units (four). The results showed that the data from the SUAS Census and the answers from the online questionnaires are congruent, in terms of occupational therapists' professional characteristics. The practices identified from the different stages provided a set of information, included: reception, workshops, individual and family follow-ups, home visits, and intersectoral network articulation. Three analyzes categories were elaborated on the characteristics of the work of occupational therapists. Is expected that the characterization of the practices of social services workers, as specified here by occupational therapists, can offer subsidies for the qualification of the actions paths for all professionals that integrate social services as executors of social protection policy.
\end{abstract}

Keywords: Social occupational therapy. Social policy. Professional practice. Unified social assistance system.

\footnotetext{
* Graduação em Terapia Ocupacional pelo Centro Universitário Claretiano de Batatais. Doutorado em Terapia Ocupacional pela Universidade Federal de são Carlos. Professora Adjunta do Departamento de Terapia Ocupacional da Universidade Federal do Triângulo Mineiro.

** Graduação em Terapia Ocupacional pela Universidade Federal de São Carlos. Doutorado em Saúde Pública pela Universidade de São Paulo. Professora Associada do Departamento de Terapia Ocupacional e do Programa de Pós-Graduação em Terapia Ocupacional da Universidade Federal de São Carlos (UFSCar).
} 


\section{Introdução}

As políticas de proteção social se originaram no reconhecimento dos riscos sociais implicados ao trabalho na sociedade capitalista, expandindo-se a partir a segunda metade do século XX, expressando os antagonismos e as contradições entre as classes sociais (MOTA; MARANHÃO; SITCOVSKY, 2010).

No contexto do capitalismo monopolista, a política social se estruturou em um conjunto de respostas que buscou mediar os interesses em disputa na sociedade diante das expressões da "questão social" (NETTO, 2009). Neste processo, apresentou-se como meio de socializar os custos de produção para os capitalistas e como ferramenta para a manutenção do tecido social e do status quo pelo Estado, reivindicada pelos trabalhadores por meio da luta por condições dignas de vida (BEHRING; BOSCHETTI, 2011; BOAVENTURA, 2018).

Atualmente, a proteção social pública se expressa no Brasil por meio do sistema de seguridade social que se constitui em "ações compensatórias" voltada às pessoas que não podem prover seu sustento pelo trabalho, de "cobertura de riscos" para as situações de invalidez, doenças, acidentes e desemprego temporário e "manutenção da renda", por aposentadoria, morte ou suspenção do trabalho (MOTA; MARANHÃO; SITCOVSKY, 2010, p. 181).

As bases históricas desta estruturação demonstram que particularmente a área de assistência social enfrentou resistências para se constituir como direito, em virtude da lógica caritativa e de subvenções constituídas e mantidas (MESTRINER, 2001). Essas subvenções se efetivaram (e se efetivam) por meio de "parcerias" público-privadas, na realização de convênios e repasses de recursos. A transferência de inciativas socioassistenciais para a sociedade civil, mediante a precariedade ou ausência da assistência estatal, possibilitou (e ainda possibilita) a execução de "práticas voluntárias, filantrópicas e caritativas, de ajudamútua ou autoajuda" (MONTAÑO, 2002, p. 4).

Destaca-se que o componente liberal, no processo de individualização das responsabilidades pelas condições sociais, foi determinante para fragilizar a estruturação da assistência social como política pública no Brasil (MESTRINER, 2001).

A Constituição Federal de 1988 confere à assistência social o status de política de seguridade social, junto à previdência e à saúde (SPOSATI, 2007), conforme descrito no artigo 194: "A seguridade social compreende um conjunto integrado de ações de iniciativa dos 
Poderes Públicos e da sociedade, destinadas a assegurar os direitos relativos à saúde, à previdência e à assistência social." (BRASIL, 1988, p. 102).

Desde a promulgação da Constituição um longo caminho de avanços e retrocessos marcaram a assistência social até a aprovação da Política Nacional de Assistência Social (PNAS) em 2004 (BRASIL, 2004) e sequencialmente a instituição do Sistema Único de Assistência Social (SUAS), em 2005. O SUAS organiza a oferta de serviços e programas vinculados à assistência social, de forma pública e não contributiva a quem dela necessitar, como direito dos cidadãos e dever do Estado (CNAS, 2005). Sem adentrar nos méritos das críticas sobre a efetividade e cobertura deste tipo de organização, compreende-se que o SUAS foi fruto de uma construção histórica do campo socioassistencial brasileiro, permeado por valores e experiências que tanto impulsionaram sua existência, como apontaram para a necessidade de rupturas com um passado benemerente, confessional e voluntarista. Contudo, ainda se vivencia um processo em curso entre o princípio assistencialista e a lógica da garantia de direitos, tanto na transição histórica no nível legislativo, quanto na concepção do imaginário social do povo brasileiro (CHIACHIO, 2011).

No âmbito do SUAS, em 2011 foi aprovada a resolução 17, do Conselho Nacional de Assistência Social (CNAS), que ratificou a Norma Operacional Básica dos Recursos Humanos (NOB/SUAS/RH) e regulamentou a inserção de profissionais que atuavam em unidades socioassistenciais ${ }^{1}$. No que se refere à composição dessas equipes, dados do Censo SUAS ${ }^{2}$ de 2018 revelam que 10,9\% dos trabalhadores eram assistentes sociais, 7,6\% psicólogos e 81\% outros profissionais, entre eles observa-se uma crescente participação de terapeutas ocupacionais (BRASIL, 2018).

Para a operacionalização do SUAS, tendo em vista a composição multiprofissional da rede socioassistencial, coloca-se a questão sobre quais têm sido as características e a função dos profissionais na execução da política de assistência social, como representantes para a consecução da proteção social estabelecida juridicamente pela Constituição. Salienta-se que tal princípio só poderá ser alcançado por meio de ações interdisciplinares construídas sob

\footnotetext{
${ }^{1}$ Categorias profissionais de nível superior que, preferencialmente, poderão atender às especificidades dos serviços: Antropólogo, Economista Doméstico, Pedagogo, Sociólogo, Terapeuta Ocupacional e Musicoterapeuta. Categorias profissionais de nível superior que, preferencialmente, poderão compor a gestão: Assistente Social, Psicólogo, Advogado, Administrador, Antropólogo, Contador, Economista, Economista Doméstico, Pedagogo, Sociólogo, Terapeuta Ocupacional.

2 Informações mais atuais no momento da obtenção dos dados. Informações das Unidades de acolhimento encontravam-se organizadas em RH Estadual e Municipal, tendo sido somados.
} 
lógicas e responsabilidades ético-políticas que não fragmentem o sujeito usuário da política de assistência social (CFESS, 2011).

Valorizando o trabalho desenvolvido por equipes, o presente estudo enfoca especificamente na ação de terapeutas ocupacionais, que, embora não componham de forma predominante os quadros profissionais dos diferentes serviços, têm apresentado um crescimento anual de sua participação no SUAS, trazendo desafios internos para a categoria, assim como externos, na medida que assume junto a outros profissionais a construção e efetivação desta política. A terapia ocupacional pode ser definida como:

[...] um campo de conhecimento e de intervenção em saúde, educação e na esfera social, reunindo tecnologias orientadas para a emancipação e autonomia de pessoas que, por razões ligadas à problemática específica, físicas, sensoriais, mentais, psicológicas e/ou sociais apresentam temporariamente ou definitivamente dificuldade da inserção e participação na vida social (CREFITO, 2020).

A inserção da terapia ocupacional em serviços vinculados à assistência social tem um histórico comum à própria institucionalização da profissão no país (ALMEIDA, et al., 2012; GALHEIGO, 2016), com particularidades no que tange à população acompanhada, majoritariamente, em seu processo histórico, pessoas com deficiências e com transtornos mentais. Inicialmente os profissionais integraram equipes de instituições socioassistenciais com caráter filantrópico e caritativo, como APAEs (Associação de Pais e Amigos dos Excepcionais), Sociedade Pestalozzi, asilos, entre outros. Sendo que as populações tradicionalmente acompanhadas por aqueles locais tinham pouco reconhecimento sobre seus direitos sociais. O que, dentre outros fatores, influenciou o imaginário que as pessoas acompanhadas pelos terapeutas ocupacionais eram, e ainda são, por vezes, caracterizadas pela dimensão da caridade e não pela dimensão dos seus direitos e cidadania (MALFITANO; FERREIRA, 2011).

Nesse contexto, enfatiza-se que a inserção dos terapeutas ocupacionais se deu historicamente junto às equipes de Organizações Não Governamentais (ONGs), muitas das quais se constituem com cunho filantrópico ${ }^{3}$. As ONGs representaram no Brasil um modelo de intervenção dominante no campo social, com ampla proposição de parcerias com o Estado,

\footnotetext{
3 Segundo Montaño (2002, p. 56), o chamado terceiro setor, onde se localizam as Organizações Não Governamentais (ONGs) e as Organização da Sociedade Civil de Interesse Público (OSCIPs), consolidou-se em modalidades de serviços que têm qualidades associadas, entre essas está o filantrópico/voluntário, em que geralmente se atribui uma qualidade "inferior" aos serviços privados.
} 
consistindo em um importante campo de trabalho empregador de terapeutas ocupacionais (BORBA; LOPES, 2016).

De forma geral, considera-se que a incorporação deste profissional no sistema público (inicialmente de forma mais preponderante na saúde, em função da regulamentação do Sistema Único de Saúde - SUS) e a atuação em instituições privadas filantrópicas (ou não), sobretudo em ONGs, marcaram as características do seu ingresso no âmbito das políticas sociais, em especial da assistência social.

Apesar de estar historicamente em serviços socioassistenciais, o reconhecimento formal dos terapeutas ocupacionais na configuração política da assistência social é recente, sendo que os movimentos para a inserção regulamentada nesta política pública ocorreram na última década. Nos anos de 2010 e 2011, trabalhadores se engajaram em movimentos sociais e de representação da classe profissional para se somar às lutas em prol de um novo contorno da política de assistência social, apresentando suas construções já realizadas naquele campo e possibilidades técnicas para compor tais espaços. Dentre estas mobilizações destaca-se o trabalho desenvolvido em eventos regionais, estaduais e no Encontro Nacional dos Trabalhadores do SUAS, que ocorreu em 30 e 31 de março de 2011, em Brasília (ALMEIDA et al., 2012; CNAS, 2007). Na plenária final do Encontro Nacional foram apresentadas as profissões reconhecidas como trabalhadores do SUAS e os encaminhamentos daquele evento subsidiaram a já mencionada Resolução 17 do Conselho Nacional de Assistência Social, aprovada em 20 de junho de 2011. Entre as categorias, "a terapia ocupacional figurou como profissão que pode integrar as equipes de referência, respeitando-se a necessidade de estruturação e composição dos serviços a partir das particularidades locais e regionais, do território e das necessidades dos usuários." (ALMEIDA, et al., 2012, p. 34; BRASIL, 2011; CNAS, 2011).

Desta forma, salientando a importância de conhecer as diferentes possibilidades de atuações que podem compor as equipes do SUAS, para se contribuir com a efetivação da proteção social, delineou-se o objetivo deste estudo em: identificar, descrever e analisar características de inserção e práticas de terapeutas ocupacionais em unidades socioassistenciais que compõem a rede SUAS.

\section{Percurso Metodológico}


A fundamentação teórico-metodológica para o desenvolvimento desta pesquisa foi inspirada nas contribuições do materialismo histórico-dialético. Segundo Frigotto (2000), a dialética se constitui como uma postura, como um método e como práxis na busca pela elaboração de sínteses que possam gerar transformações na esfera do conhecimento e da realidade histórica. Estes constructos orientam o entendimento sobre como se produz concretamente um fenômeno social e a relação com o seu caráter histórico. Trata-se de realizar movimentos de transformação e superação por meio da crítica, da construção de novos conhecimentos e da síntese no campo do conhecimento e da ação (FRIGOTTO, 2000).

Com isto, a presente pesquisa buscou a produção de sínteses acerca da atuação do terapeuta ocupacional no SUAS com vistas a contribuir com as discussões sobre as possibilidades de aprimoramento do trabalho nos serviços de assistência social, na direção da consolidação do direito constitucional estabelecido no país.

Como métodos, inicialmente realizou-se um levantamento em base de dados oficiais do Ministério do Desenvolvimento Social $(\mathrm{MDS})^{4}$, por meio do Censo SUAS, a fim de se obter informações sobre o número de terapeutas ocupacionais vinculados ao sistema no país. Este procedimento foi realizado em 2017, e, portanto, os dados mais recentes naquele momento eram referentes a 2016, quando se constatou a presença de 1.323 profissionais. De posse desta informação, a coleta de dados ocorreu em três etapas realizadas junto a terapeutas ocupacionais que atuavam no SUAS, a saber: I) Questionários online, II) Entrevistas e III) Observação das práticas em quatro campos de atuação.

\section{Etapa I - Questionários online}

Foram enviados eletronicamente questionários para os profissionais identificados no levantamento inicial, de quem se obteve o contato (e-mail ou telefone) e que aceitaram participar do estudo. Na tentativa de alcançar o maior número de trabalhadores para o envio dos questionários foram realizados os seguintes procedimentos: 1) Divulgação do questionário por meio do levantamento de uma lista de terapeutas ocupacionais em redes sociais $\left(\right.$ Facebook $^{\circledR} /$ WhatsApp $^{\circledR}$ ) e 2) Contato com as unidades socioassistenciais que contavam com terapeutas ocupacionais em sua equipe, por meio do telefone institucional.

\footnotetext{
${ }^{4}$ Atual Ministério da Cidadania, por meio da Secretaria Especial do Desenvolvimento Social.
} 
Este segundo procedimento foi possível por meio da articulação com a base de dados do CadSUAS ${ }^{5}$, sendo elaborada uma nova tabela com os contatos telefônicos, e-mails institucionais dos serviços e os nomes. Utilizando esta tabela, buscou-se contatar todas as unidades identificadas ( $n=1.323$ ). Para isso, foram realizadas ligações telefônicas em todos os estabelecimentos, excluindo-se as unidades repetidas na base de dados e aquelas que após cinco tentativas em dias e horários distintos não se obteve sucesso, sendo considerada uma primeira tentativa apenas quando a ligação era realizada com o número telefônico mais provável de ser o correto, tendo os dados sido atualizados, quando necessário, pela internet, por meio do sítio eletrônico das prefeituras e também por ligações telefônicas diretamente nas prefeituras e secretarias dos municípios e estados. Ressalta-se o esforço das tentativas para acessar a totalidade dos terapeutas ocupacionais por meio dos procedimentos adotados para o contato, chegando-se à estimativa do alcance de 762 convites à participação na pesquisa (58\%).

Foi obtido o retorno de 242 questionários preenchidos e válidos para a pesquisa. Em uma perspectiva amostral ${ }^{6}$ desta etapa do estudo, considera-se que em 2016 a população total de terapeutas ocupacionais vinculados ao SUAS era constituída por 1.323 profissionais, em um cenário probabilístico, utilizando a Amostragem Aleatória Simples (o que constitui uma análise em que todos os valores amostrados teriam a mesma chance de serem obtidos) utilizando o "P" igual a 0,5, o tamanho amostral seria de 225 profissionais, o que possibilitaria dizer que o total de participantes (242) seria mais que o suficiente para conseguir inferir os resultados sobre a população. Apontou-se, no entanto, que a divulgação realizada do estudo em redes sociais $\left(\right.$ Facebook $^{\circledast}$ e WhatsApp ${ }^{\circledR}$ ) pode ter alterado a possibilidade de todos os terapeutas ocupacionais terem a mesma chance de serem colaboradores do estudo, caracterizando uma amostragem não probabilística por conveniência.

\section{Etapa II - Entrevistas}

\footnotetext{
${ }^{5}$ Informações no site: https://aplicacoes.mds.gov.br/cadsuas/.

6 A amostragem estatística é uma ferramenta que trabalha com ambientalização, estudo de erros e confiabilidade. Analisa-se, com especificidade de caso, o todo (população) por meio de apenas alguns indivíduos (amostra) selecionados de determinada maneira. Por essa amostra se consegue obter indícios de algum comportamento da população ou até mesmo a possível variabilidade dos interferentes. Nos métodos de amostragem existem dois pilares: a Amostragem Probabilística e a Amostragem Não Probabilística (BOLFARINE; BUSSAB, 2005).
} 
A partir das respostas provenientes aos questionários (Etapa I) foi realizada a seleção de 12 profissionais convidados a participar de uma entrevista utilizando um roteiro elaborado previamente pelas pesquisadoras. O objetivo foi aprofundar a discussão das informações, tendo em vista a especificidade dos serviços em que eles estão inseridos.

O procedimento de seleção dos terapeutas ocupacionais para participar da entrevista foi: 1) verificação dos questionários que estavam completamente preenchidos; e 2) análise de respostas mais completas por unidades socioassistenciais, sendo selecionados dois de cada unidade (Centro Dia, Centro Pop, Centro de Referência de Assistência Social - CRAS, Centro de Referência Especializada em Assistência Social - CREAS, Unidade de Acolhimento e Centro de Convivência). Naquele momento, foram selecionados preferencialmente os que atuavam como terapeutas ocupacionais, em relação ao cargo de gestão e/ou educador social.

Dos 12 convidados, dois não retornaram o convite e uma pessoa alegou não ter disponibilidade para participar. Assim, para contemplar pelo menos um entrevistado de cada tipo de unidade, foi convidada posteriormente outro profissional, inserida em um Centro de Convivência. Dessa forma, efetivaram-se 10 entrevistas realizadas pessoalmente, via Skype ${ }^{\circledR}$,

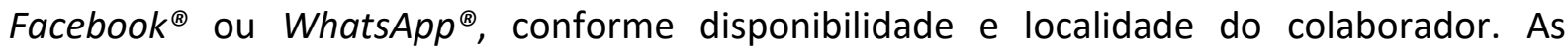
entrevistas totalizaram a duração de 1.075 minutos (aproximadamente 18 horas), sendo que todas foram gravadas (áudio) e transcritas, resultando em 219 páginas.

No momento final de cada entrevista foi solicitado aos colaboradores que fizessem a indicação de alguém que teria destaque na área ou que fosse uma referência para sua prática na assistência social. Tal solicitação compôs o processo de indicações de locais para observação em campo, a Etapa III da pesquisa.

\section{Etapa III - Visitas para acompanhamento das práticas}

Identificou-se que a visita in loco se tratava de uma etapa fundamental para a complementação dos dados, na medida em que se buscava se aproximar da realidade vivida em diferentes serviços, para além de uma visão mais numérica da inserção do terapeuta ocupacional no SUAS. Foram selecionados quatro profissionais, de diferentes unidades socioassistenciais no estado de São Paulo, para desenvolver o acompanhamento das suas atividades.

Foi utilizada uma fonte mista de indicações: respostas dos questionários, devolutivas das entrevistas e participantes de etapas anteriores que tivessem demonstrado 
disponibilidade, apresentando respostas completas às questões apresentadas. Salienta-se que a realização das visitas/acompanhamentos foi pautada na indicação de pessoas com práticas referenciadas como positivas na assistência social.

Optou-se pela delimitação dos profissionais atuantes na região Sudeste, particularmente no estado de São Paulo. Esta opção se deu em decorrência de ser o estado com maior número de terapeutas ocupacionais que atuam no SUAS (60\% no Sudeste e $36 \%$ no estado de São Paulo, em 2017) (BRASIL, 2017b), além de acumular o maior quantitativo de colaboradores participantes desta pesquisa (questionários, $72 \%$ e entrevistas, $50 \%$ ).

Foram realizadas visitas presenciais nos locais de trabalho das terapeutas ocupacionais colaboradoras, em um processo de observação pelo período de uma semana.

\section{Resultados e Discussão}

\section{A Inserção e Prática de Terapeutas Ocupacionais no SUAS}

Por meio de análises do período entre 2011 e 2017, na base de dados do Censo SUAS, verificou-se maior concentração de terapeutas ocupacionais vinculados à assistência social atuando na região Sudeste (37\% em 2011, 50\% em 2012, 47\% em 2013, 57\% em 2014, 60\% em 2015, 61\% em 2016 e 60\% em 2017) em contraposição com a região Norte (3\% em 2011 e 2012, 5\% em 2013, 3\% em 2014, 1\% em 2015, 2\% em 2016 e 2017) (OLIVEIRA; PINHO; MALFITANO, 2019).

Em relação à inserção nas diferentes unidades socioassistenciais ${ }^{7}$, identificou-se a prevalência de profissionais em Centros Dia e Unidades de Acolhimento, respectivamente. Cabe destacar que os dados são apresentados de forma heterogênea ao longo dos anos no Censo SUAS, sendo identificado a partir de 2012 a inserção das informações referentes às Unidades de Acolhimento e apenas no ano de 2015 sobre o Centro Dia, que desde então se destaca quantitativamente no que se refere à presença de terapeutas ocupacionais em suas equipes (48\% em 2015, 45\% em 2016 e 53\% em 2017). O local com menores números absolutos são os Centros Pop (3\% em 2011, 1\% em 2012 e em 2013, 3\% em 2014, 1\% em 2015, 2016 e 2017) (OLIVEIRA; PINHO; MALFITANO, 2019). A categoria, que trabalha no setor de

\footnotetext{
${ }^{7}$ Considerando CRAS, CREAS, Centro Pop, Centro de Convivência, Centro Dia e Unidade de Acolhimento.
} 
assistência social, é composta majoritariamente por mulheres ${ }^{8}$, constituindo $93 \%$ em 2017 (BRASIL, 2017b).

Realizando um paralelo entre os dados do Censo SUAS e as respostas provenientes dos 242 questionários online constatou-se que os resultados se mostram congruentes em relação ao gênero e demais características, como a prevalência de terapeutas ocupacionais trabalhando na região Sudeste, nos Centros Dias, exercendo a função de técnicos de nível superior, com a carga horária semanal prevalente entre 30 a 39 horas semanais e vínculo empregatício como celetistas.

No que tange às características mencionadas, infere-se que as colaboradoras perfazem um grupo que pode ser representativo da integralidade das profissionais terapeutas ocupacionais que atuavam no SUAS; enfatizando-se, assim, a relevância das informações descritas a seguir sobre as práticas, que buscam apresentar uma compreensão ampliada acerca do trabalho que tem sido realizado atualmente na assistência social.

De forma geral, as práticas diárias promovidas pelas terapeutas ocupacionais na assistência social, identificadas nas diferentes etapas de campo da pesquisa, abarcaram: acolhidas, acompanhamentos individuais, familiares, visitas domiciliares, articulação em rede intersetorial e trabalho com grupos/oficinas. Para apresentar mais detalhadamente as informações dos questionários, entrevistas e visitas foram elaboradas três categorias de análises sobre algumas das características do trabalho no SUAS que tiveram maior destaque pela frequência nos discursos e vivências, sendo elas: 1) O trabalho de terapeutas ocupacionais com/no cotidiano, 2) A atuação profissional com grupos/oficinas e 3) A articulação em redes como ação profissional na assistência social.

\section{O Trabalho de Terapeutas Ocupacionais com/no Cotidiano}

As práticas profissionais, na realidade do dia-a-dia das unidades socioassistenciais, se efetivam diante dos múltiplos desafios revelados por problemáticas complexas que decorrem das desigualdades estruturais e históricas engendradas no sistema econômico político e social, expressando-se na ausência ou fragilidade do acesso aos direitos, na pobreza e miséria, em violências, abusos, intolerâncias, preconceitos, subjugações, entre outros.

\footnotetext{
${ }^{8}$ Tendo em vista tais informações sobre a presença majoritária de mulheres entre os terapeutas ocupacionais que atuam na assistência social, optou-se por utilizar textualmente a marcação feminina de gênero em menção às participantes do estudo, sem desconsiderar a abrangência dos profissionais desta pesquisa. Assim, utilizouse o feminino ao se referir ao conjunto de colaboradores/as dos diferentes gêneros.
} 
Os relatos, observações e vivências nesta pesquisa possibilitaram o contato com o trabalho de terapeutas ocupacionais e consequentemente com perspectivas sobre a identificação de características de atuação na realidade concreta de suas rotinas, que indicaram proposições sustentadas na materialidade da vida dos sujeitos/famílias/grupos/coletivos acompanhados por meio de atuações no/com os cotidianos.

Em uma perspectiva analítica sobre as práticas referidas acredita-se que nas impossibilidades de romper com a dureza de processos macroestruturais são criadas possibilidades, quiçá microresistências cotidianas, no agir junto aos sujeitos em direção à promoção de proteções sociais em frestas possíveis de acessar e que se tem apropriação profissional para se fazer, na medida em que se refere a um dos objetos centrais de estudo e intervenção do terapeuta ocupacional, ou seja, nos cotidianos de vida.

Neste sentido, as atuações se concretizaram nas camadas triviais do cotidiano, como na organização de horários de transporte para que uma usuária de um Centro Dia para Pessoas com Deficiência não permanecesse desacompanhada enquanto aguardava diariamente sua prima/tutora chegar do trabalho; ou na sugestão/estruturação/mediação de processos para viabilizar a ida de uma criança à creche, para que a mãe efetivasse uma organização sobre seus afazeres de trabalho. Com esta orientação, foi apreendido, pelos discursos e acompanhamentos das colaboradoras, vivências que favoreceram a relação com o(s) Outro(s) e com os serviços, fomentando e articulando redes sociais de suporte.

Compreendeu-se que as intervenções voltadas para as dimensões cotidianas apoiaram possibilidades de ampliação das sociabilidades (primária e secundária), conforme definido por Castel (2015), contribuindo para a criação/ampliação/fortalecimento das redes sociais de suporte dos usuários e suas famílias. Nos exemplos brevemente mencionados anteriormente, a organização dos horários junto à usuária visou a menor exposição a riscos de violações de seus direitos, o que foi efetivado a partir da articulação entre o serviço, familiares e vizinhos (sociabilidade primária e secundária). No segundo caso, a proposição para mediação entre a usuária e a creche se deu pela indicação de momentos ao longo do dia em que fosse possível retomar atividades de interesse, visando ao favorecimento da sua organização cotidiana com base no estabelecimento de redes de suporte sociais formais (secundárias) que pudessem proporcionar vivências de maior autonomia e menor privação financeira. Entende-se que as relações sociais (nas esferas da sociabilidade primária e 
secundária) são estabelecidas, ou não, na dinamicidade da vida, na trama da construção dos cotidianos.

Propondo-se delinear e ilustrar com maior detalhamento como ocorre a intervenção assim direcionada das profissionais, resgata-se um fragmento sobre uma das situações mencionadas, relativa aos acompanhamentos que compuseram as narrativas relativas às visitas in loco no Centro dia.

\begin{abstract}
Terapeuta ocupacional e assistente social do Centro Dia] identificaram incialmente riscos sociais nos momentos em que Daniela ficava na rua sozinha, aguardando o transporte do lado de fora da casa. Apontaram então a primeira estratégia de contatar a prima para realizar orientações e concomitantemente buscar averiguar com Daniela formas de sua autoproteção, como fortalecer suas iniciativas para realizar pedidos de ajuda. [...] Foram identificadas ao longo da semana situações de vulnerabilidade de Daniela no retorno para sua residência e, assim, no último dia da minha permanência, a equipe técnica conseguiu agendar, para o próximo dia útil, uma visita domiciliar para conversar pessoalmente com a familiar, objetivando apoiar a função protetiva e tomar as demais providências cabiveis ao caso. (Trecho do diário de campo, utilizando nome fictício para a usuária. Acompanhamento da terapeuta ocupacional que atua no Centro Dia).
\end{abstract}

Compreende-se que a atuação da terapeuta ocupacional no Centro Dia, por exemplo, considerou elementos que compuseram as relações estabelecidas no cotidiano de Daniela para buscar promover sua proteção social, sendo que os pormenores do dia a dia da usuária, nas atividades que realizava, foram os pontos-chave de ação propostos.

Adotando essa perspectiva, dialoga-se com Galheigo (2003, p. 108), na compreensão do conceito de cotidiano na terapia ocupacional, implicado com uma perspectiva crítica para a "retomada histórica e contextualizada do sujeito e sua inserção participante no coletivo". Com o mesmo direcionamento, Salles e Matsukura (2013, p. 268) delinearam que o cotidiano se estabelece "na relação entre aquilo que é singular do sujeito com o que é coletivo e social". Compreendendo que a vulnerabilidade permeia "as ações mais ordinárias do cotidiano" dos sujeitos-coletivos (COSTA, 2016, p. 141), o acompanhamento da usuária se deu, por exemplo, na estruturação de horários junto à equipe, análise para proposição de novas agendas e articulações com a família, com cuidadoras, transporte e vizinhos, explicitando uma dimensão concreta do agir junto no/com o cotidiano dos atores envolvidos na situação. Essa atuação junto à família da usuária foi atravessada por processos macrossociais, como aqueles situados, por exemplo, nas vulnerabilidades inerentes às 
questões de gênero, culturais e socioeconômicas que incidem naquela comunidade e na sociedade.

Como pode ser observado, as respostas produzidas no âmbito da assistência social articuladas ao cotidiano dos sujeitos podem estar associadas a diferentes espaços: nos territórios, nas famílias, nos serviços públicos e em diferentes lugares em que "as relações sociais se fortalecem ou se fragilizam" (BRASIL, 2017a, p. 14). Nessa intervenção, a profissional pareceu buscar o fortalecimento de Daniela e os suportes sociais familiares, bem como de sua vizinhança, para que esta mulher tivesse minimizados os riscos de ter novamente seus direitos violados, expandindo a potencialidade do que Castel (2015) denominou como sociabilidade primária.

Pautando-se em Castel (2015) para fundamentar a leitura das informações sobre a atuação em relação às vulnerabilidades sociais, compreende-se que as redes sociais de suporte podem se desenvolver tanto a partir do eixo da inscrição sociofamiliar, baseadas na dimensão relacional, como pelo eixo do trabalho. Na defesa das políticas e direitos sociais, Castel assume como pilares de sua teoria o trabalho e o suporte relacional sociofamiliar, para compreender os eixos de integração/não integração social. "Estar dentro da zona de integração significa dispor de garantias de um trabalho permanente e que se pode mobilizar suportes relacionais sólidos; a zona de vulnerabilidade associa precariedade do trabalho e fragilidade relacional; a zona de desfiliação conjuga a ausência de trabalho e isolamento social" (CASTEL, 1994, p. 30, grifos do autor). Articulando os resultados da pesquisa com esses pilares estruturantes para a coesão social (CASTEL, 2015), verificou-se que as terapeutas ocupacionais colaboradoras têm atuado em menor proporção na dimensão trabalho/renda e mais consistentemente na criação/ampliação/fortalecimento das redes sociais de suporte.

Especificamente sobre intervenções acerca da criação de trabalho, os dados da pesquisa apontaram apenas dez relatos, oriundos do questionário online, os quais explicitamente abordaram a economia solidária, em específico oficinas para geração de renda. Portanto, a grande maioria das práticas descritas revela um movimento majoritário das terapeutas ocupacionais na assistência social voltado para as redes sociais de suportes. Observa-se, entretanto, que a categoria possui potencial para contribuir na criação de suportes para o trabalho, ao fortalecer, ampliar e qualificar iniciativas como as apresentadas na perspectiva de oficinas relacionadas à economia solidária, por exemplo. 
Dessa forma, com base nos acompanhamentos e se reportando novamente a Castel, compreende-se que as intervenções ocorreram prioritariamente em direção à promoção da proteção social, voltadas às ações que mobilizaram as redes sociais de suporte, tanto no âmbito da sociabilidade primária quanto secundária (CASTEL, 2015).

\section{A atuação Profissional com Grupos/Oficinas}

O trabalho com grupos/oficinas em diferentes serviços socioassistenciais marcou amplamente os discursos sobre as práticas das terapeutas ocupacionais na assistência social, podendo-se inferir que foram utilizados como uma importante estratégia para a criação/ampliação/fortalecimento das redes sociais de suporte.

É importante saber trabalhar em grupo, conceito de grupo, porque eu acho que o grupo é muito potente, mas também muito difícil. Então acho que buscar referências de trabalho em grupo é muito importante. No trabalho em grupo, mesmo ele não sendo terapêutico, é bem difícil conduzir um grupo em geral, ser criativo, saber trabalhar em equipe. (Trecho de uma das respostas da entrevista. Terapeuta Ocupacional que atua no CRAS).

Embora a realização de grupos e oficinas não seja considerada uma ação específica no escopo profissional terapêutico-ocupacional, sua formação fornece ferramentas necessárias para que os desenvolvam no contexto da assistência social. As informações do estudo permitem constatar que a realização de grupos de atividades, mesmo não sendo exclusivamente atribuída às profissionais, apresentou-se como uma das características da atuação no setor, sendo uma das práticas mais realizadas em diferentes unidades do SUAS, presente em $84 \%{ }^{9}$ das ações descritas.

Ao se referir ao trabalho com grupos, atenta-se para o fato de que o termo abrange múltiplas possibilidades/modalidades para a realização dessa atividade. Teixeira (2010), em um estudo sobre o trabalho interdisciplinar em CRAS, aponta que:

O trabalho com grupos implica várias modalidades de trabalho em grupos e de acompanhamentos, desde os grupos socioeducativos para a família e seus representantes, até núcleos socioeducativos, com espaço de escuta, de acolhimento, da fala, de reflexão, discussões, aprendizagem; grupos lúdicos, de socialização, de convivência com crianças, adolescentes, jovens e idosos que demandam oficinas de reflexões, reuniões, palestras, campanhas socioeducativas, dentre outros (TEIXEIRA, 2010, p. 193).

\footnotetext{
9 Totalizaram 204 os profissionais que mencionaram "grupos" nas respostas à questão "Quais tipos de acompanhamentos os terapeutas ocupacionais realizam nesta unidade?".
} 
Esta variedade compôs as práticas das colaboradoras em diferentes unidades, ilustradas a seguir com trechos de respostas do questionário online.

\begin{abstract}
Mediação de processos grupais: grupos de convivência, oficina de jogos cooperativos, grupos de sensibilização (terapia socioassistencial), roda de conversa troca de experiências, atendimento às famílias. (Trecho de uma das respostas do questionário online. Terapeuta ocupacional que atua em Centro de Convivência). Dinâmicas e vivências, vídeos, músicas, acolhida, apresentações dialogadas, oficinas de artesanato, grupo de atividades, a depender da demanda e perfil dos grupos. (Trecho de uma das respostas do questionário online. Terapeuta ocupacional que atua em CRAS).

Rodas de conversa, grupos focais, atendimento individual. (Trecho de uma das respostas do questionário online. Terapeuta ocupacional que atua em CRAS).
\end{abstract}

Os exemplos buscaram retratar a multiplicidade das atividades na modalidade grupal desenvolvidas pelas terapeutas ocupacionais no setor. Essas informações permitem indicar que os grupos e oficinas expressam possibilidades de intervenções criativas nos caminhos de atuação nas vulnerabilidades sociais apresentadas pelos usuários e suas famílias, alinhadas com as demandas da assistência social e com enfoque nas esferas relacionais e em seus cotidianos.

Segundo os pressupostos da Terapia Ocupacional Social ${ }^{10}$, Lopes (2016, p. 45), delineou que o profissional lança mão de Oficinas de Atividades, Dinâmicas e Projetos, recorrendo ao potencial da atividade, uma vez que "a dimensão sociopolítica e cultural dos diferentes fazeres permeia os cotidianos, favorecendo a autovalorização dos sujeitos e possibilitando a produção de vida com sentidos, com vistas à emancipação pessoal e social". Ilustra-se com o excerto a seguir.

\begin{abstract}
O artesanato só era meio, então isso ficou muito nítido! Porque não é que pouco importava o que elas faziam, mas na verdade, importava muito o que elas queriam fazer. [...] Na maior parte das vezes eu não "ensinava" as atividades, eram elas mesmas. Então eu falava "Quem é que sabe fazer isso? Trazendo essa conscientização de que elas tinham potencial e fortalecer isso, uma ensinar para a outra, as trocas [...]. E eu dava suporte, orientação, estava muito mais nos relacionamentos entre elas, com as formas de lidar, porque eram muitas as fragilidades. [...] Começaram a levar as práticas para fora, então elas faziam ali o grupo comigo, mas se encontravam nas casas para fazer as atividades, porque para
\end{abstract}

\footnotetext{
${ }^{10}$ A Terapia Ocupacional Social pode ser considerada uma subárea da terapia ocupacional com possibilidade para refletir e informar as práticas na assistência social em sua amplitude de serviços que compõem o SUAS. A Terapia Ocupacional Social busca fundamentar ações que visem à inserção e participações sociais dos sujeitos, podendo se voltar ao princípio da proteção social, observando os limites estruturais da sociedade desigual em que vivemos e suas inerentes condições (MALFITANO, 2016).
} 


\begin{abstract}
fazer artesanato não precisavam de mim; precisavam para ajudar a se relacionar e diminuir as tensões e melhorar a convivência. Serem mais reflexivas com as coisas que elas faziam e não faziam. Mostrava, por exemplo, que eu não estava ali fazendo um favor, "Isso é direito de vocês, o que vocês têm são direitos que são assegurados!" e começar a trabalhar esse posicionamento, esse empoderamento deles, de direitos sociais. Eram deles! E sobre os posicionamentos, muitas vezes a gente os viu se posicionando frente a autoridades [...], então eles começaram a conseguir se posicionar, se expressar. (Trecho de uma das respostas da entrevista. Terapeuta Ocupacional que atua no Centro de Referência do Idoso).
\end{abstract}

Neste relato, a terapeuta ocupacional apresentou o artesanato como recurso mediador das relações, explicitando o potencial das atividades na terapia ocupacional para a produção de convivência, de autonomia, de "emancipação pessoal e social" (LOPES, 2016, p. 45).

Infere-se que os diferentes grupos/oficinas podem possibilitar os fazeres compartilhados, despertando interesses, oportunidades e a construção de laços relacionais que incidem no cotidiano por meio das trocas favorecidas e mediadas pelas terapeutas ocupacionais. Estes espaços promovem a convivência e o entrelaçar de conexões junto a pessoas das comunidades (sociabilidade primária), sustentada inicialmente pelo serviço (sociabilidade secundária) e, por vezes, extrapolada para os espaços de vida, como descrito no excerto acima. Desse modo, o trabalho com grupos pode favorecer a criação e/ou ampliação de redes sociais de suporte, apoiando conexões relacionais formais e informais naquela comunidade e, a depender dos vínculos constituídos, componentes que possibilitem maior grau de proteção social.

As ações em grupos destacadas pelas profissionais estão em concordância com as práticas preconizadas no setor nos diferentes níveis assistenciais, constando nos diferentes Cadernos de Orientações Técnicas disponíveis no sítio eletrônico da Secretaria Especial do Desenvolvimento Social ${ }^{11}$, referente às unidades CREAS, Centro Pop, CRAS (incluindo os documentos sobre o PAIF), serviços de acolhimento, entre outros.

Dessa forma, valoriza-se este tipo de ação ressaltando a potencialidade da modalidade de acompanhamento grupal para favorecer a promoção da convivência, da construção/consolidação dos vínculos, apoiando consistentemente a mediação para a criação/ampliação/fortalecimento das redes sociais de suporte formais e informais. Salienta-

${ }^{11}$ Site: http://mds.gov.br/central-de-conteudo/assistencia-social/publicacoes-assistencia-social 
se que tanto a convivência ${ }^{12}$ quanto o fortalecimento de vínculo ${ }^{13}$ foram objetivos que permearam as práticas das colaboradoras, não apenas nos grupos/oficinas, mas também em diferentes espaços socioassistenciais.

\section{A Articulação em Redes como Ação Profissional na Assistência Social}

A articulação das redes setoriais e intersetoriais destacou-se como uma das ações extensivamente presente nas práticas das colaboradoras, verificada em todas as entrevistas (100\%), visitas (100\%) e parte dos questionários online (26\%). Assim, a articulação da rede pode ser considerada também uma característica da prática da terapia ocupacional na assistência social. Infere-se que essa articulação se deu como um dos fundamentos para uma atenção integral relacionada à sociabilidade secundária, fundamental para ampliação/fortalecimento da rede social de suporte dos sujeitos.

De acordo com a PNAS, a articulação da rede dos serviços socioassistenciais, com base no território, constitui-se um caminho para superar fragmentações existentes na assistência social (BRASIL, 2004). Segundo Giaqueto (2010, p. 96) “a rede surge da percepção conjunta dos problemas comuns e da possibilidade de resolvê-los de maneira integrada. Por isso que a linguagem da rede é uma linguagem de vínculos."

Entende-se que a rede de serviços do SUAS, descrita na Tipificação Nacional dos Serviços Socioassistenciais e organizada em Proteção Social Básica e Especial (de média e alta complexidades), busca garantir a integralidade da atenção socioassistencial. O itinerário desenvolvido no percurso dessa rede pode ser qualificado/otimizado por articulações consistentes, pautadas na comunicação adequada entre os serviços, em que os técnicos têm possibilidades de buscar os suportes para responder às demandas sociais dos sujeitos e suas famílias em outros equipamentos e equipes, de acordo com a finalidade e nível de complexidade de cada um deles.

Já a articulação realizada entre outras políticas públicas setoriais pode ser compreendida como aquelas que acontecem por meio do referenciamento e contra referenciamento de outros setores, como a saúde e a educação. Atenta-se que a assistência

\footnotetext{
${ }^{12}$ A convivência pode ser compreendida como um processo e como uma metodologia na assistência social para desenvolver os acompanhamentos nos diferentes tipos de serviços socioassistenciais (BRASIL, 2017, p. 56).

${ }^{13}$ O fortalecimento de vínculos na assistência social reafirma a necessidade de lidar com vulnerabilidades no âmbito relacional como uma responsabilidade pública, integrante a uma política que busca combater desigualdades e promover o desenvolvimento da sociedade (BRASIL, 2017b; CASTEL, 2015).
} 
social, na composição da seguridade social, constitui-se uma política de proteção social, como a previdência e a saúde. Desta forma, considera-se que "prover proteção social não é especificidade de uma única política, em seu sentido pleno, ela vai acontecer somente de forma integrada com as demais políticas, pois os riscos sociais fazem parte do campo de relações da vida humana." (VELHO, 2018, p. 73). Sendo assim, a intersetorialidade é uma das bases para a busca de proteção social.

A articulação entre setores se mostrou uma prática amplamente mencionada nas respostas das terapeutas ocupacionais, corroborando sua relevância na composição das ações técnicas. Uma das colaboradoras diz:

Quando temos [terapeutas ocupacionais] que fazer as reuniões de rede, as construções da rede, conseguimos construir porque conseguimos conversar com facilidade com todas as áreas, temos um pouco da compreensão delas [...]. Já na formação, a gente tem contato com um pouquinho de cada área e consegue entender e conversar com facilidade com todas elas (Trecho de uma das respostas da entrevista. Terapeuta ocupacional que atua no Centro de Referência do Idoso).

\section{Considerações Finais}

Conclui-se que os objetivos propostos foram abarcados na identificação e descrição sobre as características de inserção das terapeutas ocupacionais no SUAS, evidenciando as regiões do país (Sudeste) e unidades socioassistenciais (Centros Dia) em que predominantemente atuam. Sobre as práticas, identificou-se variados tipos de ações desenvolvidas: acolhidas, acompanhamentos individuais, familiares, visitas domiciliares, articulação em rede intersetorial e trabalho com grupos/oficinas. No âmbito da diversidade dessas ações, algumas características marcaram as suas práticas, destacando-se, de forma mais analítica, as atuações voltadas aos cotidianos dos sujeitos, o trabalho com grupos e a articulação das redes para a consecução dos objetivos das diferentes unidades.

Apreendeu-se, considerando a complexidade das problemáticas sociais, que a atuação de terapeutas ocupacionais, quando voltada para as redes sociais de suporte, possui potencial para operar por meio de elementos que possam contribuir para minimizar e/ou superar situações de vulnerabilidades sociais caminhando no sentido da promoção da proteção social. Sendo que tais contribuições se integram às equipes de cada unidade, na direção de efetivarem a proteção social esperada pelos princípios estabelecidos pelo SUAS. 
Espera-se que a caracterização sobre as práticas das trabalhadoras da assistência social, aqui especificadas as terapeutas ocupacionais, possa oferecer subsídios para disparar reflexões sobre a qualificação dos caminhos de intervenção, bem como a criação de espaços de diálogo, por meio de articulações em rede com profissionais vinculados ao SUAS. Compreende-se que a identificação, análises e revisões sobre as práticas técnico-profissionais são de grande relevância para a totalidade de categorias que integram a assistência social como executores da política de proteção social.

\section{Referências}

ALMEIDA, M. C. de; SOARES, C. R. S.; BARROS, D. D.; GALVANI, D.. Processos e práticas de formalização da Terapia Ocupacional na Assistência Social: alguns marcos e desafios. Cadernos Brasileiros de Terapia Ocupacional, São Carlos, v. 20, n. 1, p. 33-41, 2012. doi: 10.4322/cto.2012.004.

BEHRING, E. R.; BOSCHETTI, I. C. Políticas sociais: fundamentos e história. 9. ed. São Paulo: Cortez, 2011. 213 p. (Biblioteca básica de serviço social, v. 2).

BOAVENTURA, F. E. Precarização do trabalho e (des)proteção social no Brasil contemporâneo. 2018. 197 f. Tese (Doutorado em Política Social) - Universidade de Brasília, Brasília, 2018.

BOLFARINE, H.; BUSSAB, W. de O. Elementos de amostragem. São Paulo: ABE; Edgard Blücher, 2005. 290p.

BORBA, P. L. de O.; LOPES, R. E. Possíveis lugares para o terapeuta ocupacional nas Organizações Não Governamentais. In: LOPES, R. E.; MALFITANO, A. P. S. (org.). Terapia ocupacional social: desenhos teóricos e contornos práticos. São Carlos: EDUFSCar, 2016. p. 241-254.

BRASIL. [Constituição (1988)]. Constituição da República Federativa do Brasil. Brasília, DF: Centro Gráfico, 1988.

BRASIL. Ministério do Desenvolvimento Social - MDS. Concepção de convivência e fortalecimento de vínculos. Brasília, DF, 2017b. 76 p. Disponível em: http://www.mds.gov.br/webarquivos/publicacao/assistencia_social/Cadernos/concepcao_f ortalecimento_vinculos.pdf. Acesso em: 30 jan. 2019.

BRASIL. Ministério do Desenvolvimento Social - MDS. Portal Censo SUAS. Publicações Censo 2010-2017. Brasília, DF: MDS, 2017a. Disponível em:

https://aplicacoes.mds.gov.br/sagirmps/portal-censo/. Acesso em: 23 mar. 2018.

BRASIL. Ministério do Desenvolvimento Social e Combate à Fome - MDS. Norma Operacional Básica de Recursos Humanos do Sistema Único de Assistência Social: Anotada e Comentada. Brasília, DF: MDS, 2011b. 144p. Disponível em: 
https://www.mds.gov.br/webarquivos/publicacao/assistencia_social/Normativas/NOBRH_SUAS_Anotada_Comentada.pdf. Acesso em: 30 jan. 2019.

BRASIL. Ministério do Desenvolvimento Social e Combate à Fome. Resolução n. 145 de 15 de outubro de 2004. Aprova a Política Nacional de Assistência Social. Brasília, DF: Presidência da República, 2004. Disponível em: https://www.mds.gov.br/webarquivos/ publicacao/assistencia_social/Normativas/PNAS2004.pdf. Acesso em: 30 jan. 2019.

BRASIL. Ministério do Desenvolvimento Social. Vigilância Socioassistencial. Bases e Resultados do Censo SUAS 2018. Brasília: MDS, 2018. Disponível em:

http://aplicacoes.mds.gov.br/snas/ vigilancia/index2.php. Acesso em: 5 mar. 2020.

CASTEL, R. As metamorfoses da questão social: uma crônica do salário. Tradução de Iraci D. Poleti. 12. ed. Petrópolis: Vozes, 2015. 611 p.

CASTEL, R. Da indigência à exclusão, a desfiliação, precariedade do trabalho e a vulnerabilidade relacional. In: LANCETTI, A (org.). Saúde e loucura 4. São Paulo: Editora Hucitec, 1994. p. 21-48.

CFESS - CONSELHO FEDERAL DE SERVIÇO SOCIAL. Parâmetros para atuação de Assistentes Sociais na Política de Assistência Social. Brasília - DF: CFESS, 2011. (Série: Trabalho e Projeto Profissional nas Políticas Sociais).

CHIACHIO, N. B. A construção dos serviços de assistência social como política social pública. 2011. 228 f. Tese (Doutorado em Serviço Social) - Pontifícia Universidade Católica de São Paulo, São Paulo, 2011.

CNAS - CONSELHO NACIONAL DE ASSISTÊNCIA SOCIAL. Resolução n. 130 de 15 de julho de 2005. Aprova a Norma Operacional Básica do Sistema Único de Assistência Social NOB/SUAS. Brasília, DF: CNAS, 2005. Disponível em: http://www.mds.gov.br/cnas/legislacao/resolucoes/arquivos-2005/resolucoes-cnas-2005/. Acesso em: 30 jan. 2019.

CNAS - CONSELHO NACIONAL DE ASSISTÊNCIA SOCIAL. Resolução $n .17$ de 20 de junho de 2011. Ratifica a equipe de referência definida pela Norma Operacional Básica de Recursos Humanos do Sistema Único de assistência Social e Reconhece as categorias profissionais de nível superior para atender as especificidades dos serviços socioassistenciais e das funções essenciais de gestão do SUAS. Brasília, DF, 2011. Disponível em:

http://www.mds.gov.br/cnas/legislacao/legislacao/resolucoes/ arquivos-2011/arquivos2011/. Acesso em: 30 jan. 2019.

CNAS - CONSELHO NACIONAL DE ASSISTÊNCIA SOCIAL. Resolução n. 172 de 20 de setembro de 2007. Recomenda a instituição de Mesa de Negociação na forma estabelecida na Norma Operacional de Recursos Humanos do Sistema Único de Assistência Social/NOB-RH/SUAS. Brasília, DF: CNAS, 2007. Disponível em: http://www.mds.gov.br/cnas/legislacao/resolucoes/arquivos-2007/resolucoes-normativasexercicio-de-2007. Acesso em: 12 dez. 2019.

COSTA, L. A. A terapia ocupacional no contexto de expansão do sistema de proteção social. 
In: LOPES, R. E.; MALFITANO, A. P. S. (org.). Terapia ocupacional social: desenhos teóricos e contornos práticos. São Carlos: EDUFSCar, 2016. p. 135-153.

CREFITO - CONSELHO REGIONAL DE FISIOTERAPIA E TERAPIA OCUPACIONAL. Terceira região (3). Definição. 2020. Disponível em: http://www.crefito3.org.br/dsn/terapiaocup.asp. Acesso em: 05 de março de 2020.

FRIGOTTO, G. O enfoque da dialética materialista histórica na pesquisa educacional. In: FAZENDA, I. (org.). Metodologia da pesquisa educacional. 6. ed. São Paulo: Cortez, 2000, p. 69-90.

GALHEIGO, S. M. O cotidiano na terapia ocupacional: cultura, subjetividade e contexto histórico-social. Cadernos Brasileiros de Terapia Ocupacional, São Carlos, v. 14, n. 3, p. 104109, 2003. doi: 10.11606/issn.2238-6149.v14i3p104-109.

GALHEIGO, S. M. Terapia Ocupacional social: uma síntese histórica acerca da constituição de um campo de saber e de prática. In: LOPES, R. E.; MALFITANO, A. P. S. (org.). Terapia ocupacional social: desenhos teóricos e contornos práticos. São Carlos: EDUFSCar, 2016. p. 49-68.

GIAQUETO, A.. A descentralização e a intersetorialidade na política de assistência social. Revista Serviço Social \& Saúde, Campinas, v. 9, n. 10, p. 79-102, 2010. doi: 10.20396/sss.v9i2.8634883.

LOPES, R. E. Cidadania, direito e terapia ocupacional social. In: LOPES, R. E.; MALFITANO, A. P. S. (org.). Terapia Ocupacional Social: desenhos teóricos e contornos práticos. São Carlos: EDUFSCar, 2016. p. 29-48.

MALFITANO, A. P. S.; FERREIRA, A. P. Saúde pública e terapia ocupacional: apontamentos sobre relações históricas e atuais. Revista de Terapia Ocupacional da Universidade de São Paulo, São Paulo, v. 22, n. 2, p. 102-109, 2011. doi: 10.11606/issn.2238-6149.v22i2p102-109.

MESTRINER, M. L.. O Estado entre a filantropia e a Assistência Social. 2. ed. São Paulo: Cortez, 2001. 320 p.

MONTAÑO, C. E. O projeto neoliberal de resposta à "questão social" e a funcionalidade do "terceiro Setor". Revista Lutas Sociais, São Paulo, n. 8, p. 53-64, 2002. Disponível em: https://revistas.pucsp.br/ls/article/view/18912. Acesso em: 9 out. 2020.

MOTA, A. E.; MARANHÃO, C. H.; SITCOVSKY, M. As tendências da política de assistência social, o SUAS e a formação profissional. In: MOTA, A. E. (org.). O mito da assistência social: ensaios sobre Estado, política e sociedade. 4. ed. São Paulo: Cortez, 2010. p. 180-198.

NETTO, J. P. Capitalismo Monopolista e Serviço Social. 7. ed. São Paulo, Cortez, 2009.

OLIVEIRA, M. L. de; PINHO, R. J. do; MALFITANO, A. P. S.. O cenário da inserção dos terapeutas ocupacionais no Sistema Único de Assistência Social: registros oficiais sobre o nosso percurso. Cadernos Brasileiros de Terapia Ocupacional, São Carlos, v. 27, n. 4, p. 828842, 2019. doi: 10.4322/2526-8910.ctoao1742. 
SALLES, M. M.; MATSUKURA, T. S.. Estudo de revisão sistemática sobre o uso do conceito de cotidiano no campo da terapia ocupacional no Brasil. Cadernos Brasileiros de Terapia Ocupacional, São Carlos, v. 21, n. 2, p. 265-273, 2013. doi: 10.4322/cto.2013.028.

SPOSATI, A.. A menina LOAS: um processo de construção de assistência social. 6. ed. São Paulo: Cortez, 2007. 84 p.

TEIXEIRA, S. M. Trabalho Interdisciplinar nos CRAS: um novo enfoque e trato à pobreza? Textos \& Contextos, Porto Alegre, v. 9, n. 2, p. 286-297, 2010.

VELHO, A. J. Z.. Acolhida social coletiva: garantia de proteção social no CRAS. 2018. 130 f. Dissertação (Mestrado em Serviço Social) - Pontifícia Universidade Católica do Rio Grande do Sul, Rio Grande do Sul, 2018. 